\title{
Prof. Dr. W. Löffler Zum 70. Geburtstag
}

Direktor der Medizinischen Uníversitäts-klinik Zurich, wird am 28. Juni 195770 Jahre alt. Redaktion und Verlag der «Cardiologia» entbieten ihm bei diesem Anlaß die best en Glückwünsche. Prof. Löffler ist noch ein Vertreter der Generation bedeutender Kliniker, welche die innere Medizin als unteilbare Wis-senschaft auffassen und eine zu starke Spezíalisíerung der ärzt-iichen Tätigkeit nicht als wünschbar betrachten.

Aus der Schule des physiologischen Chemikers Hoffmeister in Straßburg behielt Löffler stets seine Vorliebe für phijsiologisch-chemische Probleme, in der Basler Klinik von Rudolf Staehelin er-warb er sich die breiten klinischen Grundlagen, die sein klinisches Wirken später als Polikliniker und Kliniker in Zurich ausgezeich-net haben.

Der Kardiologie hat Löffler stets sein besonderes Interesse zu-gewandt. Eine Reihe von Arbeíten haben sich mít kardiologischen Fragen befaßt. Nachhaltigsten Widerhall fund die erstmalige fieschreibung der Endocarditis fibroplastica eosinophilica (Löffler), eines Krankheitsbildes, welches heute nach seinem Namen benannt ist. Andere kardiologische Arbeiten befaßten sich mít Problemen der Endocarditis, des Herzinfarkts, therapeutischen Fragen und diagnostischen Problemen. Prof. Löffler hat, aus eigener An-schauung und durch eígene Arbeíten bereichert, eínen weiten Weg der modernen Kardiologie miterlebt und mitgefördert.

Es ist nicht die Aufgabe einer kardiologischen Zeitschrift, das gesamte wissenschaftliche Lebenswerk Löfflers, das einen großen Bezirk der inneren Medizin umfaßt, darzustellen. Hingegen dürfen bei einem mit Herzkrankheiten und damit menschlichen Problemen im weitesten Sinne sich beschåftigenden Kliniker die allge-mein kulturellen und humanistischen Interessen nicht unerwähnt bleiben. Als Politiker vertritt Löffler se.it víelen Jahren die ärztlichen Interessen ím Zürcher Gemeinderat und verficht eine frei-heitliche, durch staatliche Fesseln nicht allzu eingeengte Berufs-auffassung; als Kunstkenner besitzt er eine überragende Klee-Sammlung, als aktives Mitglied von Kommissionen mit verschie-densten Aufgaben kämpft er stets für vernünftige und tragbare

Entscheídungen. Die rasche Erfassung des Wesentlichen, die poin-tiette, niiancierte Darstellungsgabe baslerischer Prägung und die umfassende Bíldung prädestinieren Löfl'ler für die Skizzierung eines Problems in einer besonderen und unerreichten Weise. Wír wissen, daß uns Lðffler mit dieser Gabe, wenn er von der täglichen Routinearbeit entlastet íst, in noch reichem Maße beglücken wird, und wír freuen uns auf die an französischen Vorbildern geschulten líteraríschen Werke.

R. Hegglín. S. Karger Verlag,

Dr. Heinz Karger. 